\title{
Values, preferences and goals identified during shared decision making between critically ill patients and their doctors
}

Sharyn L Milnes, Yianni Mantzaridis, Nicholas B Simpson, Trisha L Dunning, Debra C Kerr, Joan B Ostaszkiewicz, Gerry T Keely, Charlie Corke and Neil R Orford

Patients who have life-limiting illnesses (LLIs) and are admitted to an intensive care unit (ICU) are at high risk of dying in the subsequent year. ${ }^{1,2}$ Providing high quality person-centred care to these patients may improve their experience and outcomes. ${ }^{3-6}$ Participation in shared decision making (SDM), where patients' values, preferences and goals are elucidated and integrated into their medical care, assists clinicians to operationalise person-centred care, and is considered practice standard worldwide. ${ }^{6-8}$

Effective SDM requires clinicians to: elicit patient values, preferences and goals; align them with appropriate medical advice; and deliberate with patients and surrogates to achieve consensus. Although these concepts are quite simple, translating the principles of SDM into routine clinical practice is elusive in critical illness, ${ }^{9,10}$ despite the use of values tools, ${ }^{10}$ decision aids, ${ }^{11}$ patient lists $^{12}$ and SDM frameworks. ${ }^{13}$ Reasons include difficulty identifying patients with LLIs, ${ }^{14}$ clinician reluctance to initiate conversations, ${ }^{15}$ lack of communication skills (including the ability to elicit, recognise and integrate patients' values into discussion about their clinical care), ${ }^{16}$ difficulties reaching consensus ${ }^{17}$ and poor documentation. ${ }^{2}$ The effect of SDM education and clinical support programs on clinicians' ability to elicit patient values and integrate them into discussions about goals and preferences is unclear.

In this study, we aimed to examine the values, preferences and goals elicited and documented by doctors following goals-of-care (GOC) discussions with critically ill patients who had a LLI, or their surrogate, in a tertiary ICU that had an established SDM training program.

\section{Methods}

We performed a descriptive qualitative study using content analysis of GOC forms for all patients who had a LLI and had been admitted to a tertiary ICU in an academic hospital (University Hospital Geelong, Barwon Health) that services a population of about 500000 people in South Western Victoria, Australia. Qualitative content analysis is a validated data analysis method that provides structure for analysing text to identify presence, meanings and relationships of

\begin{abstract}
Objective: Examine values, preferences and goals elicited by doctors following goals-of-care (GOC) discussions with critically ill patients who had life-limiting illnesses.

Design: Descriptive qualitative study using four-stage latent content analysis.

Setting: Tertiary intensive care unit (ICU) in South Western Victoria.
\end{abstract}

Participants: Adults who had life-limiting illnesses and were admitted to the ICU with documented GOC, between October 2016 and July 2018.

Intervention: The iValidate program, a shared decisionmaking clinical communication education and clinical support program, for all ICU registrars in August 2015.

Main outcome measures: Matrix of themes and subthemes categorised into values, preferences and goals.

Results: A total of 354 GOC forms were analysed from 218 patients who had life-limiting illnesses and were admitted to the ICU. In the categories of values, preferences and goals, four themes were identified: connectedness and relational autonomy, autonomy of decision maker, balancing quality and quantity of life, and physical comfort. The subthemes - relationships, sense of place, enjoyment of activities, independence, dignity, cognitive function, quality of life, longevity and physical comfort - provided a matrix of issues identified as important to patients. Relationship, place, independence and physical comfort statements were most frequently identified; longevity was least frequently identified.

Conclusion: Our analysis of GOC discussions between medical staff and patients who had life-limiting illnesses and were admitted to the ICU, using a shared decision-making training and support program, revealed a framework of values, preferences and goals that could provide a structure to assist clinicians to engage in shared decision making.

Crit Care Resusc 2021; 23 (1): 76-85 


\section{ORIGINAL ARTICLES}

words and concepts, and then make inferences about the message in the particular context, goal or environment in which it was produced. ${ }^{18}$ Ethics approval was obtained from the institutional human research ethics committee before commencing the study.

\section{Inclusion and use of GOC forms}

GOC forms analysed in this study were included if the patient: was an adult (aged > 18 years) who had a LLI (Online Appendix, Table 1); was admitted to the ICU between October 2016 and July 2018; had text documented on their GOC form. The iValidate program is a SDM education and clinical support program that has been described previously. ${ }^{2,19}$ The education program teaches communication skills for SDM and is based on the Calgary-Cambridge model for the clinical interaction. ${ }^{20}$ It is based on an adult education pedagogy and uses the agenda-led outcome-based analysis (ALOBA) method of teaching in an interactive, small group, scenario-based roleplay workshop. The clinical support includes documentation to match the model taught for SDM, standard items in daily ICU treatment meeting, visual aids for staff, visitors and patients in the ICU, and spot audits of GOC quality for ICU patients who have a LLI. The iValidate program commenced at University Hospital Geelong in August 2015, and all ICU registrars were required to complete the course. The GOC form was developed to reinforce a SDM process, and requires documentation to demonstrate the key phases of a SDM process and the treatment plan for deterioration. These are: (i) identify patients with a LLI using objective criteria; (ii) assess patient decision-making capacity and, where required, identify a surrogate decision maker; (iii) document evidence of SDM; and (iv) document a deterioration plan (Online Appendix, Figure 1). Usual practice is for clinicians to complete the GOC form during or immediately after a GOC discussion with a patient and/ or their medical treatment decision maker.

\section{Data collection and analysis}

We collected data on patient demographics, clinical characteristics, and completion of each step in the GOC form. GOC forms were extracted from the ICU electronic medical records and de-identified by one of us (YM). Data were collected and managed using REDCap electronic data capture tools. ${ }^{21,22}$

Open text from GOC forms was analysed using a four-stage qualitative content analysis. ${ }^{18}$ Researchers used conventional qualitative analysis processes (online Supporting Information, Text 1). Initial analysis of 20 forms was performed by five of us (SLM, YM, NRO, NBS, GTK) we read and re-read the text to gain a sense of the data, and then met to agree on themes and subthemes. A coding tool was developed, and data were sorted using Excel 2015 (Microsoft).

Two of us (YM, SLM) then coded the remaining forms. Discrepancies were resolved via rechecking by two of us (NRO, NBS [clinical researchers]). Data saturation was reached when no new codes emerged. One of us (SLM) completed the content analysis guided by the following framework (online Supporting Information, Text 1): 18

- de-contextualisation

- identifying meaning units

- creating code list

- re-contextualisation

- including content and comparing to identify themes through deductive analysis

- excluding dross content

- triangulation by researchers

- categorisation

- identifying homogenous groups

- compilation

- drawing realistic conclusions

- member checking.

\section{Results}

We reviewed medical records for 326 patients, and included in the study 354 GOC forms from 218 ICU patients who had a LLI (Figure 1). The demographic and clinical characteristics of included patients are shown in Table 1. In our content analysis, we identified three categories and four themes. The categories were values, preferences and goals, and the themes were: connectedness and relational autonomy, autonomy of decision maker, balancing quality and quantity of life, and physical comfort. Definitions for categorisation are provided online (Online Appendix, Table 2). A selection of statements is presented for each theme and category in Table 2, and distribution of statements within themes and subthemes is shown in Table 3.

\section{Themes}

Connectedness and relational autonomy. This was the dominant theme, indicating a sense of connectedness to people, place or endeavour. Meaning units present in subthemes included statements about relationships, sense of place and enjoyment of activities.

Statements identifying the importance of relationships were present in all categories. Values statements referred to the importance and enjoyment that patients placed on time with their family. The importance of not becoming a burden on family was a recurring goal statement. Other 


\section{ORIGINAL ARTICLES}

\section{Figure 1: Flow and inclusion of patients and GOC forms in the study}

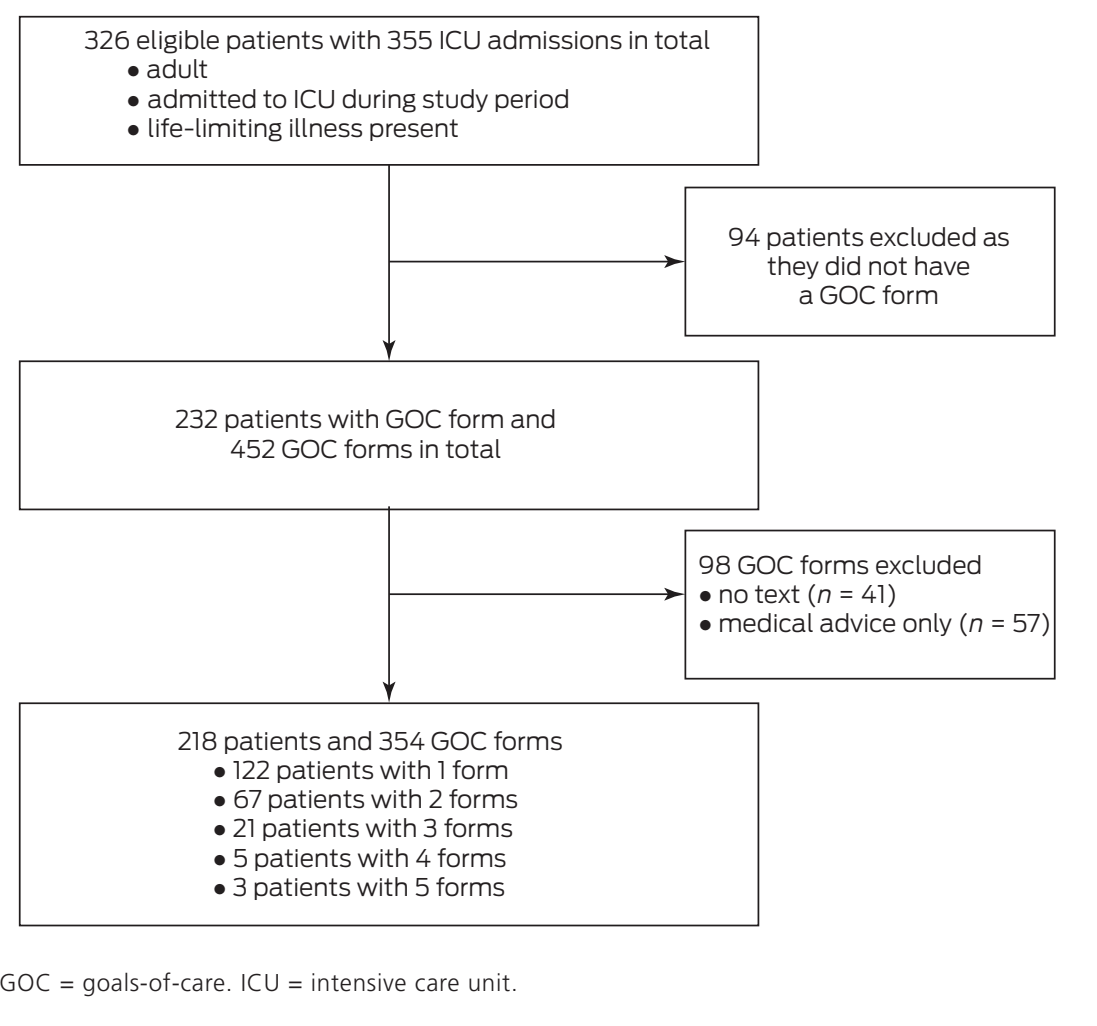

Statements in the subtheme of place occurred in all categories and related to a desire to return to place of residence and not remain in hospital. Place of residence before hospital admission included the patient's own home, a residential aged care facility (RACF), a local health facility, and the residence of a family member. Value statements conveyed a sense of the patients' enjoyment of time and presence in the place they called home - most specifically related to their own home, rather than an RACF or living in the residence of their adult children. Comments included:

[Patient name] values her time at home with usual "stuff".

Values being home in whatever capacity.

Place-related preference statements focused on location of care such as regional or rural health facilities closer to the patient's home and community. Goal statements indicated patient wishes to return to their place of residence and/or the probability and desire to die at home goal statements referenced particular events that patients wanted to live for and share with their families. Relationship treatment preference statements often included level of intensive care support linked to a goal. For example:

Values being at home and spending time with his grandchildren.

Values ability to interact with son.

Not to be burden on family and left in debilitating state.

Wants to get to Gold Coast [a holiday destination in Australia] with family in 3 weeks.

Would like to see grandchild born in May.

Would not want to be a burden or have life prolonging treatment unless a reasonable chance of recovery.

Willing for other ICU support in order to see grandchildren grow up. or in their RACF. Comments included:

Would like ongoing care closer to family in Lorne [coastal town in Victoria, Australia].

Does not want any more care in hospital. Would prefer to have care back at [the] Lodge [RACF].

Not to travel outside Hamilton [rural town] in future for medical care.

He wants to live at his home with his dogs.

To be well enough to travel home to the Philippines.

To be back at daughter's home.

Hates hospitals and eager to return to Lodge [RACF]. "If I'm going to die then take me back there."

Knows her disease will eventually kill her and she stated she wants to die at home and "... not in hospital with tubes and things sticking out of me." 


\section{ORIGINAL ARTICLES}

\begin{tabular}{|c|c|}
\hline \multicolumn{2}{|c|}{$\begin{array}{l}\text { Table 1. Patient demographics and clinical } \\
\text { characteristics* }\end{array}$} \\
\hline Variable & $\begin{array}{l}\text { Participants } \\
(n=326)\end{array}$ \\
\hline Age (years) & $68(59-76)$ \\
\hline Women & $150(46 \%)$ \\
\hline \multicolumn{2}{|l|}{ Pre-hospital accommodation } \\
\hline Home & $267(82 \%)$ \\
\hline RACF & $18(6 \%)$ \\
\hline Other & $41(13 \%)$ \\
\hline Advance care plan & $68(21 \%)$ \\
\hline \multicolumn{2}{|l|}{ Life-limiting illness trajectory } \\
\hline Cancer & $80(25 \%)$ \\
\hline \multicolumn{2}{|l|}{ Frailty } \\
\hline Physical frailty & $115(35 \%)$ \\
\hline Dementia & $6(2 \%)$ \\
\hline Resides in RACF & $4(1 \%)$ \\
\hline \multicolumn{2}{|l|}{ Organ failure } \\
\hline Congestive cardiac failure & $38(12 \%)$ \\
\hline COPD & $77(24 \%)$ \\
\hline Renal failure & $39(12 \%)$ \\
\hline Stroke & $6(2 \%)$ \\
\hline Parkinson disease, MS or MND & $3(1 \%)$ \\
\hline \multicolumn{2}{|l|}{ ICU characteristics } \\
\hline APACHE III score & $65(47-87)$ \\
\hline Mechanical ventilation & $98(30 \%)$ \\
\hline Mechanical ventilation duration (h) & $40(15-85)$ \\
\hline CRRT & $31(10 \%)$ \\
\hline ICU length of stay (days) & $2(1-4)$ \\
\hline \multicolumn{2}{|l|}{ Hospital characteristics } \\
\hline MET call & $113(35 \%)$ \\
\hline Palliative care referral & $51(16 \%)$ \\
\hline Hospital length of stay (days) & $9(5-15)$ \\
\hline 90-day re-admission & $130(40 \%)$ \\
\hline \multicolumn{2}{|l|}{ Post-hospital accommodation } \\
\hline Home & $159(49 \%)$ \\
\hline RACF & $37(11 \%)$ \\
\hline Other & $42(13 \%)$ \\
\hline \multicolumn{2}{|l|}{ Mortality } \\
\hline ICU & $57(18 \%)$ \\
\hline Hospital & $88(27 \%)$ \\
\hline 90-day & $113(35 \%)$ \\
\hline
\end{tabular}

APACHE = acute physiology and chronic health evaluation. $C O P D=$ chronic obstructive pulmonary disease. CRRT = continuous renal replacement therapy. $\mathrm{ICU}=$ intensive care unit. $\mathrm{MET}=$ medical emergency team. MS = multiple sclerosis. $\mathrm{MND}=$ motor neuron disease. $\mathrm{RACF}=$ residential aged care facility. * Data are median (interquartile range) or number (percentage).

The subtheme of enjoyment of activities consisted entirely of values statements, indicating activities that gave patients pleasure. For example:

He values walking down to [the betting venue] and talking to his mates.
Would still value life if he could watch television ... Enjoys fishing and watching his grandson race cars.

Autonomy of decision maker. This theme related to maintaining a sense of self and being seen by others as a unique individual who is able to maintain selfdetermination. Self-determination included undertaking activities independently, maintaining cognitive function, and making both routine and significant decisions for oneself. The subthemes were independence, dignity and cognitive ability. Independence was the most frequent subtheme in this theme, and most statements about independence occurred in the values category and directly referred to independence as a requirement to live well. For example:

Values independence and mobility.

Retaining independence and an ability to engage meaningfully with life is important.

Preference statements all related to potential treatment administered to achieve the functional outcome of independence. A measurable level of acceptable function or dependence was rarely documented and was mainly written as "independence". Comments included the following, and comments such as the second example were frequently documented:

Does not want intervention that preserves life at the cost of independence.

Only for therapies that maintain independence.

He and his wife have a clear desire for him not to require full time care and would like to maintain his current level of independence.

Goal statements were directed toward what a patient would not tolerate as an outcome. Only three forms indicated a functional level that could be considered a measurable outcome for the patient in terms of outcome goals. These were:

Would not tolerate someone else looking after her hygiene or toileting.

He would not tolerate being cared for by his children or in a nursing home [RACF].

Does not want to lose any more independence.

Not to require feeding. Not to be bed or wheelchair bound. 


\section{ORIGINAL ARTICLES}

Table 2. Examples of meaning units per theme, subtheme and category

\begin{tabular}{|c|c|c|c|c|}
\hline \multirow[b]{2}{*}{ Theme } & \multirow[b]{2}{*}{ Subtheme } & \multicolumn{3}{|c|}{ Category } \\
\hline & & Values & Preferences & Goals \\
\hline \multirow{6}{*}{$\begin{array}{l}\text { Connectedness } \\
\text { and relational } \\
\text { autonomy }\end{array}$} & \multirow[t]{3}{*}{ Relationships } & \multirow[t]{3}{*}{ Interact with family } & \multirow{3}{*}{$\begin{array}{l}\text { Willing for [intensive care unit] } \\
\text { support to see grandchildren grow } \\
\text { up }\end{array}$} & Not be a burden [on] family \\
\hline & & & & Alive to see grandchild born \\
\hline & & & & $\begin{array}{l}\text { Get to Gold Coast with family in } 3 \\
\text { weeks }\end{array}$ \\
\hline & \multirow[t]{2}{*}{ Sense of place } & \multirow[t]{2}{*}{$\begin{array}{l}\text { Values being home in whatever } \\
\text { capacity }\end{array}$} & \multirow[t]{2}{*}{$\begin{array}{l}\text { Would like ongoing care closer to } \\
\text { family in Lorne }\end{array}$} & $\begin{array}{l}\text { Wants to die at home and "not in } \\
\text { hospital with tubes and things sticking } \\
\text { out of me" }\end{array}$ \\
\hline & & & & $\begin{array}{l}\text { He wants to live at his home with his } \\
\text { dogs }\end{array}$ \\
\hline & $\begin{array}{l}\text { Enjoyment of } \\
\text { activities }\end{array}$ & $\begin{array}{l}\text { Enjoys fishing and watching his } \\
\text { grandson race cars }\end{array}$ & - & - \\
\hline \multirow[t]{4}{*}{$\begin{array}{l}\text { Autonomy of } \\
\text { decision maker }\end{array}$} & \multirow[t]{2}{*}{ Independence } & \multirow[t]{2}{*}{ Values her independence } & \multirow{2}{*}{$\begin{array}{l}\text { Does not want intervention } \\
\text { that preserves life at the cost of } \\
\text { independence }\end{array}$} & $\begin{array}{l}\text { Would not tolerate someone else } \\
\text { looking after her hygiene or toileting }\end{array}$ \\
\hline & & & & $\begin{array}{l}\text { Not to require feeding. Not to be bed } \\
\text { or wheelchair bound }\end{array}$ \\
\hline & Dignity & She values dignity in death & - & Wants to die with dignity \\
\hline & Cognitive function & - & $\begin{array}{l}\text { Would not want treatment if it } \\
\text { meant she could not communicate } \\
\text { and make decisions for herself in } \\
\text { the long term }\end{array}$ & $\begin{array}{l}\text { Would not (tolerate) being unable } \\
\text { to verbally communicate with and } \\
\text { understand his family }\end{array}$ \\
\hline \multirow[t]{2}{*}{$\begin{array}{l}\text { Balancing quality } \\
\text { and quantity of } \\
\text { life }\end{array}$} & Quality of life & Values quality over quantity & $\begin{array}{l}\text { [Does] not want life prolonging } \\
\text { treatments that are burdensome, } \\
\text { prolonged, and result in poorer } \\
\text { quality of life }\end{array}$ & $\begin{array}{l}\text { Considers nursing home placement } \\
\text { not consistent with quality of life }\end{array}$ \\
\hline & Longevity & $\begin{array}{l}\text { Values prolonging his life, no } \\
\text { matter the complications }\end{array}$ & $\begin{array}{l}\text { For full [intensive care unit] therapies } \\
\text { if means he will live longer }\end{array}$ & $\begin{array}{l}\text { Wants us to do everything we can for } \\
\text { him to live }\end{array}$ \\
\hline Physical comfort & Physical comfort & - & $\begin{array}{l}\text { Has trialled [non-invasive ventilation] } \\
\text { over the past few days and hates it } \\
\text { and "would rather die" }\end{array}$ & $\begin{array}{l}\text { Hope for him to be comfortable and } \\
\text { not suffering }\end{array}$ \\
\hline
\end{tabular}

Would like to be able to mobilise from bed to toilet.

Not worth living if can't sit out of bed, watch TV or talk to family.

Most dignity statements were categorised as goals, with few values statements, and none indicating a preference related to treatment. The goal statements were not always a directive for a treatment or care decision and would require more exploration. Comments included:

Values maintaining his dignity.

She values dignity in death.

Maintaining cognitive function was documented as a treatment preference and goal. This included preference statements specific to treatments that patients would not want and that related to an unacceptable outcome. It also included goal statements that were related to avoiding a "vegetative state" and maintaining the ability to communicate and make decisions. No values statements relating to cognitive function were identified in the documentation. Documentation included:

Wants to remain cognitively intact.

Would not (tolerate) being unable to verbally communicate with and understand his family. [Author, we changed parentheses to brackets, assuming this word has been changed from original.

Only for ICU therapies if reasonable outcome and not vegetative.

Would not want treatment if it meant she could not communicate and make decisions for herself in the long term.

Doesn't want vegetative state. 


\section{ORIGINAL ARTICLES}

\begin{tabular}{|c|c|c|c|c|c|}
\hline Theme & Subtheme & Values & Preferences & Goals & Total \\
\hline \multirow{3}{*}{$\begin{array}{l}\text { Connectedness } \\
\text { and relational } \\
\text { autonomy }\end{array}$} & Relationships & 123 & 19 & 32 & 174 \\
\hline & Sense of place & 51 & 12 & 83 & 146 \\
\hline & Enjoyment of activities & 96 & 0 & 0 & 96 \\
\hline \multirow{3}{*}{$\begin{array}{l}\text { Autonomy of } \\
\text { decision maker }\end{array}$} & Independence & 96 & 8 & 12 & 116 \\
\hline & Dignity & 4 & 0 & 15 & 19 \\
\hline & Cognitive function & 0 & 28 & 66 & 94 \\
\hline \multirow{2}{*}{$\begin{array}{l}\text { Balancing quality } \\
\text { and quantity of life }\end{array}$} & Quality of life & 55 & 13 & 14 & 82 \\
\hline & Longevity & 0 & 4 & 9 & 13 \\
\hline Physical comfort & Physical comfort & 0 & 47 & 89 & 136 \\
\hline Total & & 425 & 131 & 320 & 876 \\
\hline
\end{tabular}

For full ICU therapies if it means he will live longer.

Surgery to save life.

Physical comfort. This theme was referred to as a preference or goal. Treatment preference statements related to pain, suffering and comfort relating to care in general, and specific treatments. Goal statements were less specific and related to comfort and suffering. For example:

Wants care to focus on comfort.

Would not want ongoing care if it meant prolonged suffering.

Balancing quality and quantity of life. This theme highlighted the trade-off between quality of life and longevity. The term "quality of life" was frequently documented. Most value statements for quality of life were literal, and there was no evidence that doctors explored what it meant to patients. Quality of life was a dependent factor and an independent factor for preference and goal statements, which is evident in the following quotes:

Values quality over quantity of life.

She would not want life prolonging treatments that are burdensome, prolonged and result in a poorer [quality of life].

She considers nursing home placement not consistent with quality of life.

While longevity was not a common subtheme, where present, documentation indicated the patient's desire to optimise quality of life for their remaining life. These statements were often situated with a requirement for an outcome that would be acceptable when balanced with more time alive. The preference statements in this subtheme were unique; all statements that indicated a desire for longevity were made by surrogate decision makers, rather than the patient, as exemplified by these quotes:

Strong will to live, resilient/fought hard, keen to give it a go.
Has trialled [non-invasive ventilation] over the past few days and hates it and "would rather die".

Keen to be pain free.

\section{Discussion}

In this study, we examined values, preferences and goals documented in the medical records of critically ill patients who had a LLI. They had been documented following GOC discussions with the patients or their surrogate decision maker, in a tertiary ICU with an established SDM training program. Analysis revealed a framework including relationships, sense of place, enjoyment of activities, independence, dignity, cognitive function, quality of life, longevity and physical comfort. Familiarity with a framework such as this could provide a structure to assist doctors to engage in SDM.

\section{Relation to previous research}

Since Robert Veatch (professor of medical ethics) first discussed a middle ground for decision making between patients and doctors in $1972,{ }^{23}$ medical ethicists, ${ }^{24-27}$ public have explored ways to include patients in decisions about their care. Shared decision making, with its emphasis preferences into conversations about treatment decisions, 7,29 provides a model that embodies the founding principles of mutual obligation, trust, ethical authority and responsibility. health practitioners 7,28 and accrediting organisations $5^{6,7,28}$ on identifying and integrating patient values, goals and 


\section{ORIGINAL ARTICLES}

Critical illness-associated end-of-life care planning represents a preference-sensitive decision scenario where engagement in SDM, and subsequent delivery of value-concordant care, is most likely to result in benefit. However, despite widespread recognition of the need for SDM, there is little evidence of successful incorporation of patient values, preferences and goals into treatment plans in critically ill populations. ${ }^{13,30}$

A major barrier to successful SDM may be the clinicians' ability to elicit and recognise patient values, and integrate them into advice, conversations and decisions about treatment preferences and outcomes. Values, goals and preferences have been identified for patient groups ${ }^{11,31-34}$ and lay people ${ }^{35}$ in various contexts, including end-oflife care, ${ }^{11,12,36}$ consumer decision aids, ${ }^{38}$ advance care planning, $33,38,39 \mathrm{GOC}$ decisions, 2,5,33,40 integrative health care $^{41}$ and ICU settings.

In the ICU setting, common domains of values relating to end-of-life care have been described and incorporated into a framework of behaviours, questions and values to assist and assess clinician engagement in SDM. ${ }^{13,43}$ These strategies have not been translated into practice: only $12-50 \%$ of ICU family conferences incorporate values and preferences when determining GOC, and treatment decisions based on patients' values occur in only $8 \%$ of cases. ${ }^{10,13,43,44}$

This study provides qualitative evidence of the values, preferences and goals identified and incorporated into conversations in an acute hospital with an established clinician education and clinical support program in clinical communication skills required for SDM. The values identified are similar to previously identified domains, but there are important differences. The subthemes of relationships, independence, dignity, cognitive function, quality of life, longevity and physical comfort are similar to previously described domains, including the relatively low importance of longevity. ${ }^{13,45-47}$

In contrast, sense of place and enjoying activities were described in a different context from previous studies. In this study, sense of place was identified as important for living well, rather than in relation to a preferred place of death. ${ }^{1,48}$ This is important in terms of care planning, as it suggests that interventions and supports which lead to a patient returning to a preferred place of residence should be prioritised independent of likelihood of survival.

Similarly, enjoying activities has been described in other studies as sense of purpose ${ }^{33}$ or wellbeing, ${ }^{47}$ while in this study doctors specifically documented activities that patients derived pleasure from. Also, spirituality and financial security were not documented as values in this study, although these have been previously identified in end-of-life conversations in other studies. ${ }^{38,49}$ This finding may represent differences in cultural or health systems, or differences in the contexts of the conversations that the studies examined.

For SDM to occur, patient values should be integrated into conversations about treatment preferences and possible outcomes. This reflects the original description by Veatch more than half a century ago:

the patient has legitimate grounds for trusting that once the basic value framework for medical decision-making is established on the basis of the patient's own values, the myriads of minute medical decisions which must be made day in and day out in the care of the patient will be made by the physician within the frame of reference. ${ }^{23}$

This is consistent with existing evidence suggesting patients and surrogates prefer preference or values-sensitive decisions over pre-determined, binary, scenario-specific decisions. This is because patients have difficulty predicting future preferences and deciding on the infinite number of possible future scenarios. ${ }^{12}$

Similarly, surrogate decision makers find it difficult to convert documented treatment preferences into specific decisions, and there is increasing evidence that patients do not wish to exert this degree of control over end-oflife decisions. ${ }^{39}$ In contrast, the values of dignity, family relationships, burden and comfort show high predictability for treatment preferences for end-of-life care. ${ }^{50}$ Patients and surrogates find it easy to translate values for living well into preferred or unacceptable outcomes, 33,51 and patient data display internal consistency for values (significantly greater than for treatment preferences) in advance care planning discussions. ${ }^{12}$ In this study, values identified in subthemes mapped to treatment and outcome preferences, supporting previously described concepts of a framework of values with related treatment preferences and goals that could be implemented clinically. ${ }^{13}$

\section{Study implications}

The framework of patient values, goals and preferences identified in this study of doctor-patient and doctorsurrogate conversations is consistent with theoretical models described for critically ill populations. Given the poor translation of SDM concepts into clinical practice and increasing recognition of the potential benefits of SDM in critically ill populations, these frameworks should be developed and tested in clinical communication education and clinical care.

\section{Strengths and limitations}

This study has several strengths and limitations. Using documented GOC discussions with critically ill patients 


\section{ORIGINAL ARTICLES}

provides valuable and in-depth insight into crucial conversations between doctors and vulnerable patients. The implementation of a structured process and communication training program enablesstandardised information gathering from patients and surrogates to guide $\mathrm{GOC}$ discussions. A limitation of this is use of clinician documentation - with the actual patient's voice (or that of their surrogate) not reported, there is potential for clinician interpretation and bias. Clinician documentation may, therefore, not be a true representation of how the patient interpreted the conversation. However, such frameworks provide a clear insight into clinician recall of patient interactions. In addition, we did not analyse the relationship between individual clinicians and content documented, creating a possible sampling bias with over-representation of "richer" text from a smaller sample of clinicians. However, as the goal of this study was to assess patient or surrogate voice, this is unlikely to be of consequence. Finally, we were not able to measure concordance of identified patient goals and/or preferences with actual treatment received, which is an important area for future research.

\section{Implications for future research}

Providing a framework of values, preferences and outcomes to assist doctors engaging in SDM may improve goalconcordant care. The framework provided by this study raises opportunities for future studies. Specifically, future research could be aim to validate values, goals and preferences in prospective and heterogenous populations, understand whether they vary with time and situation, and test their utility as a framework for hospital clinicians engaging in SDM. Finally, additional studies may lead to development of a tool for assessment of goal-concordant care - an elusive aim in person-centred care research.

\section{Conclusion}

This study of values, preferences and goals documented by doctors following GOC discussions with critically ill patients who had a LLI revealed a framework of relationships, place, enjoyment, independence, dignity, cognitive function, quality of life, longevity and physical comfort. This information could provide a structure to assist clinicians engaging in SDM.

\section{Competing interests}

None declared.

\section{Author details}

Sharyn L Milnes 1,2,3

Yianni Mantzaridis ${ }^{1}$
Nicholas B Simpson ${ }^{1,3}$

Trisha L Dunning²

Debra C Kerr²

Joan B Ostaszkiewicz ${ }^{5}$

Gerry T Keely'

Charlie Corke

Neil R Orford ${ }^{1,3,4}$

1 University Hospital Geelong, Barwon Health, Geelong, Australia.

2 Centre for Quality and Patient Safety Research, School of Nursing and Midwifery, Deakin University, Geelong, Australia.

3 School of Medicine, Deakin University, Geelong, Australia.

4 Australian and New Zealand Intensive Care Research Centre (ANZIC-RC), Department of Epidemiology and Preventive Medicine, Monash University, Melbourne, Australia.

5 National Ageing Research Institute, Melbourne, VIC, Australia.

Correspondence: sharyn.milnes@deakin.edu.au

\section{References}

1 Clark D, Armstrong M, Allan A, et al. Imminence of death among hospital inpatients: prevalent cohort study. Palliat Med 2014; 28: 474-9.

2 Orford NR, Milnes SL, Lambert N, et al. Prevalence, goals of care and long-term outcomes of patients with life-limiting illness referred to a tertiary ICU. Crit Care ResusC 2016; 18: 181.

3 Glass KE, Wills CE, Holloman C, et al. Shared decision making and other variables as correlates of satisfaction with health care decisions in a United States national survey. Patient Educ Couns 2012; 88: 100-5.

4 Heyland DK, Tranmer J, O'Callaghan CJ, Gafni A. The seriously ill hospitalized patient: preferred role in end-of-life decision making? J Crit Care 2003; 18: 3-10.

5 Orford NR, Milnes S, Simpson N, et al. Effect of communication skills training on outcomes in critically ill patients with lifelimiting illness referred for intensive care management: a before-and-after study. BMJ Support Palliat Care 2019; 9: e21.

6 Australian Commission on Safety and Quality in Health Care. Patient-centred care: improving quality and safety through partnerships with patients and consumers. Sydney: ACSQHC, 2011.

7 Institute of Medicine Committee on Quality of Health Care in America. Crossing the quality chasm: a new health system for the 21st century. Washington DC: National Academy Press, 2001.

8 Bernacki RE, Block SD. Communication about serious illness care goals: a review and synthesis of best practices. JAMA Intern Med 2014; 174: 1994-2003.

9 Kon AA. The shared decision-making continuum. JAMA 2010; 304: 903-4. 


\section{ORIGINAL ARTICLES}

10 Scheunemann LP, Cunningham TV, Arnold RM, et al. How clinicians discuss critically ill patients' preferences and values with surrogates: an empirical analysis. Crit Care Med 2015; 43: 757.

11 Ebenau AF, van Gurp JLP, Hasselaar J. Life values of elderly people suffering from incurable cancer: a literature review. Patient Educ Couns 2017; 100: 1778-86.

12 Heyland DK, Heyland R, Dodek P, et al. Discordance between patients' stated values and treatment preferences for end-oflife care: results of a multicentre survey. BMJ Support Palliat Care 2017; 7: 292-9.

13 Scheunemann LP, Ernecoff NC, Buddadhumaruk P, et al. Clinician-family communication about patients' values and preferences in intensive care units. JAMA Intern Med 2019; 179: 676-84.

14 Gibbins J, McCoubrie R, Forbes K. Why are newly qualified doctors unprepared to care for patients at the end of life? Med Educ 2011; 45: 389-99.

15 Truog R. Translating research on communication in the intensive care unit into effective educational strategies. Crit Care Med 2010; 38: 976-7.

16 Browning D, Meyer E, Truog R, Solomon M. Difficult conversations in health care: cultivating relational learning to address the hidden curriculum. Acad Med 2007; 82: 905-13.

17 Tzelepis F, Rose SK, Sanson-Fisher RW, et al. Are we missing the Institute of Medicine's mark? A systematic review of patientreported outcome measures assessing quality of patientcentred cancer care. BMC Cancer 2014; 14: 41.

18 Bengtsson $M$. How to plan and perform a qualitative study using content analysis. NursingPlus Open 2016; 2: 8-14.

19 Simpson N, Milnes S, Martin P, et al. iValidate: a communicationbased clinical intervention in life-limiting illness. BMJ Support Palliat Care 2019; doi: 10.1136/bmjspcare-2018-001669 [Epub ahead of print].

20 Silverman J, Kurtz S, Draper J. Skills for communicating with patients, 3rd ed. Boca Raton: CRC press, 2016

21 Harris PA, Taylor R, Minor BL, et al. The REDCap consortium: building an international community of software platform partners. J Biomed Inform 2019; 95: 103208.

22 Harris PA, Taylor R, Thielke R, et al. A metadata-driven methodology and workflow process for providing translational research informatics support. J Biomed Inform 2009; 42: 377-81.

23 Veatch RM. Models for ethical medicine in a revolutionary age. What physician-patient roles foster the most ethical relationship? Hastings Cent Rep 1972; 2: 5-7.

24 Ells C, Hunt MR, Chambers-Evans J. Relational autonomy as an essential component of patient-centered care. Int J Fem Approaches Bioeth 2011; 4: 79-101.

25 Elwyn G, Tilburt J, Montori V. The ethical imperative for shared decision-making. Eur J Pers Cent Healthc 2013; 1: 129-31.

26 Gillett GR. Bioethics in the clinic: Hippocratic reflections. Baltimore: Johns Hopkins University Press, 2004.

27 Sandman L, Munthe C. Shared decision-making and patient autonomy. Theor Med Bioeth 2009; 30: 289-310.
28 Gerteis M, Edgman-Levitan S, Daley J, Delbanco TL, editors. Through the patient's eyes: understanding and promoting patient-centered care. San Francisco: Jossey Bass, 2002.

29 Charles C, Gafni A, Whelan T. Shared decision-making in the medical encounter: what does it mean? (or it takes at least two to tango). Soc Sci Med 1997; 44: 681-92.

30 Kon AA, Davidson JE, Morrison W, et al. Shared decision making in ICUs: an American College of Critical Care Medicine and American Thoracic Society policy statement. Crit Care Med 2016; 44: 188-201.

31 Fried TR, Tinetti ME, lannone $L$, et al. Health outcome prioritization as a tool for decision making among older persons with multiple chronic conditions. Arch Intern Med 2011; 171: 1854-6.

32 Hanson LC, Winzelberg G. Research priorities for geriatric palliative care: goals, values, and preferences. I Palliat Med 2013; 16: 1175-9.

33 Heyland DK, Dodek P, Rocker G, et al. What matters most in end-of-life care: perceptions of seriously ill patients and their family members. CMAJ 2006; 174: 627-33.

34 Naik AD, Martin LA, Moye J, Karel MJ. Health values and treatment goals of older, multimorbid adults facing life threatening illness. J Am Geriatr Soc 2016; 64: 625-31.

35 Milnes S, Corke C, Orford N, et al. Patient values informing medical treatment: a pilot community and advance care planning survey. BMJ Support Palliat Care 2019; 9: e23.

36 Menon S, McCullough LB, Beyth RJ, et al. Use of a values inventory as a discussion aid about end-of-life care: a pilot randomized controlled trial. Palliat Support Care 2016; 14: 330-40.

37 Cardona-Morrell M, Benfatti-Olivato G, Jansen J, et al. A systematic review of effectiveness of decision aids to assist older patients at the end of life. Patient Educ Couns 2017; 100: 425-35.

38 Doukas DJ, Antonucci T, Gorenflo DW. A multigenerational study on the correlation of values and advance directives. Ethics Behav 1992; 2: 51-9.

39 Hawkins NA, Ditto PH, Danks JH, Smucker WD. Micromanaging death: process preferences, values, and goals in end-of-life medical decision making. Gerontologist 2005; 45: 107-17.

40 Morgan DJ, Eng D, Higgs D, et al. Advance care planning documentation strategies; goals of care as an alternative to not for resuscitation in medical and oncology patients. A prepost controlled study on quantifiable outcomes. Intern Med J 2018; 48: 1472-80.

41 Brooks AT, Silverman L, Wallen GR. Shared decision making: a fundamental tenet in a conceptual framework of integrative healthcare delivery. Integr Med Insights 2013: 29-36.

42 Scheunemann LP, Arnold RM, White DB. The facilitated values history: helping surrogates make authentic decisions for incapacitated patients with advanced illness. Am J Respir Crit Care Med 2012; 186: 480-6.

43 Curtis JR, Engelberg RA, Wenrich MD, et al. Missed opportunities during family conferences about end-of-life care 


\section{ORIGINAL ARTICLES}

in the intensive care unit. Am J Respir Crit Care Med 2005; 171: 844-9.

44 White DB, Braddock CH, Bereknyei S, Curtis JR. Toward shared decision making at the end of life in intensive care units: opportunities for improvement. Arch Intern Med 2007; 167: 461-7.

45 Ditto PH, Druley JA, Moore KA, et al. Fates worse than death: the role of valued life activities in health-state evaluations. Health Psychol 1996; 15: 332.

46 Fleuren N, Depla MFIA, Janssen DJA, et al. Underlying goals of advance care planning (ACP): a qualitative analysis of the literature. BMC Palliat Care 2020; 19: 27.

47 Pearlman RA, Cain KC, Patrick DL, et al. Insights pertaining to patient assessments of states worse than death. J Clin Ethics
1993; 4: 33-41.

48 Billingham MJ, Billingham SJ. Congruence between preferred and actual place of death according to the presence of malignant or non-malignant disease: a systematic review and meta-analysis. BMJ Support Palliat Care 2013; 3: 144-54.

49 Rosenfeld KE, Wenger NS, Kagawa Singer M. End of life decision making: a qualitative study of elderly individuals. J Gen Intern Med 2000; 15: 620-5.

50 Winter L. Patient values and preferences for end-of-life treatments: are values better predictors than a living will? J Palliat Med 2013; 16: 362-8.

51 You JJ, Fowler RA, Heyland DK. Just ask: discussing goals of care with patients in hospital with serious illness. CMAJ 2014; 186: 425-32. 